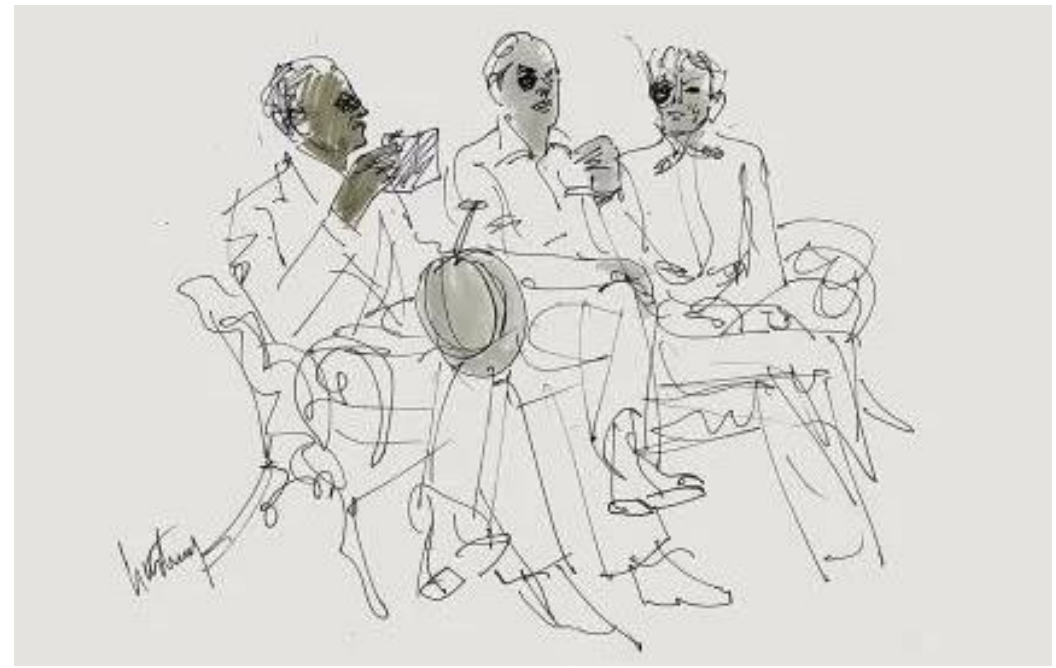

\title{
A construção de espaços provisórios na literatura latino-americana
}

The construction of provisional spaces in the Latin American literature

\author{
José Roberto Araújo de Godoy ${ }^{1}$ \\ https://orcid.org/0000-0002-5711-3992
}

\section{Resumo}

Este artigo procura investigar a construção de espacialidades como procedimento artístico, buscando inter-relações entre literatura e urbanismo. O objetivo principal é entender como determinados territórios passam a operar segundo regras próprias, e como suas peculiaridades espaciais, notadamente seu caráter provisório, se refletem em narrativas ficcionais. Determinadas "ilhas urbanas" nas cidades latino-americanas são nosso campo de investigação, em especial o bairro de Flores, em Buenos Aires, e o campus da UnB, durante o regime civilmilitar brasileiro, no final dos anos 1960 e no começo dos anos 1970. Áreas que serão relatadas pelo escritor argentino César Aira e o romancista brasileiro Milton Hatoum.

Palavras-chave: Cidades latino-americanas; narrativas latino-americanas; César Aira; Milton Hatoum; Josefina Ludmer

\begin{abstract}
This article seeks to investigate the construction of spacialities as an artistic procedure, searching for inter-relations between literature and urbanism. The main aim is to understand how some territories work by own rules, and how their spatial particularities, specially its provisional dimension, are reflected in fictional narratives. Some "urban islands" from Latin American cities are our field of investigation, specifically the district of Flores, in Buenos Aires, and the UnB (University of Brasilia) campus, along the civil-military Brazilian dictatorship, in the end of 1960's and beginning of 1970's. Places that will be reported by Argentine writer César Aira and Brazilian novelist Milton Hatoum.
\end{abstract}

Keywords: Latin American cities; Latin American narratives; César Aira; Milton Hatoum; Josefina Ludmer

\footnotetext{
${ }^{1}$ Doutorando do Programa de Literatura, Cultura e Contemporaneidade, da PUC-RJ (bolsista Capes). Mestre em Teoria Literária e Literatura Comparada pela FFLCH-USP (bolsista CNPQ). E-mail: contato@zegodoy.com.br
} 
"La creación literaria tiene leyes de perspectiva, de luz y de sombra."

César Aira

Minha proposta de análise é procurar modos de pensar a literatura produzida no continente latino-americano por meio do espaço, localizando imbricações entre um determinado conjunto de narrativas e territórios que constituem o corpo da experiência nesse espaço geográfico, histórico, político e social. Meu objetivo é investigar algumas hipóteses sugeridas por críticos e autores que vêm explorando a construção de espacialidades como procedimento artístico; as aproximações da literatura e do urbanismo como modo de compreender os modos de relatar essa dimensão territorial; e propor algumas reflexões sobre a possibilidade de unir esses campos de conhecimento apoiando-me em duas obras ficcionais: Os fantasmas, do argentino César Aira, e A noite da espera, do brasileiro Milton Hatoum.

César Aira vem produzindo no corpo de seu trabalho, tanto ensaístico quanto ficcional, uma reflexão robusta sobre a espacialidade literária. Em “Evasión”, publicado no volume de ensaios Evasión y otros ensayos, de 2017, Aira caracteriza uma determinada ideia de literatura como construção de espaços em oposição a narrativas de caráter autobiográfico, que tornaram-se um veio caudaloso da produção contemporânea. Estas últimas, argumenta Aira, têm base no discurso, e por consequência no tempo ${ }^{2}$, enquanto aquela literatura que classifica "de evasão" - um determinado conjunto de textos realizados com intuito de entreter, exemplificado pelo romance The black arrow, de Robert Louis Stevenson - é estruturada a partir da criação de cenários tridimensionais, repletos de volumes e densidade, luz e sombras, constituídos por meio de uma construção imaginária que segue "la misma lógica que hace reales a las construcciones reales" (AIRA, 2017 p. 17); espaços em que seus personagens irão encenar os seus atos ${ }^{3}$.

Trata-se ainda de uma literatura aparentada do cinema atual (ou dos best-sellers literários) em seu interesse em tornar-se um escape da realidade para seu público, e

\footnotetext{
2 "Las novelas que han adherido al círculo autobiográfico están hechas de puro tiempo, porque el yo, cuando realiza su esencia de haberse quedado solo en el mundo y sólo puede hablarse a sí mismo, espuro tempo." AIRA, César. "Evasión” In: Evasión y otros ensayos. Barcelona: Random House, 2017, p. 28, 29.

3 "Y tratando de explicarse el mecanismo figurativo que lleva adelante The Black Arrow, podría pensarse en una producción cinematográfica. En una novela como esta, una novela que pretende, y logra, llevarnos a la aventura, transportarnos a sus escenas, provocar la 'momentánea suspensión de la incredulidad' que pedía Coleridge, hay muchos rubros de los que ocuparse: el vestuario, las escenografías, el guión, los personajes, las secuencias, la iluminación, la utilería...” Idem, Ibidem, p. 12.
} 
também, quanto a seus meios e processos constitutivos, muito próxima da arquitetura. Essa semelhança está internalizada na prolífica produção de Aira, combinando-se como tema e procedimento artístico no gênero híbrido que marca seu estilo, em que constantemente se misturam e se contaminam a ficção e o ensaio, que ganham os mais diversos modos de articulação.

Em Os fantasmas, lançado na Argentina, em 1990 e no Brasil em 2017, essa dimensão arquitetônica se dará na emergência da dimensão do não construído, "a ponte dos reflexos (...) que é praticamente tudo na matéria" (AIRA, 1990, p. 66) ${ }^{4}$. O não construído, o não feito, como Aira se refere em outro de seus textos, é onde reside "o segredo utópico da arte" (AIRA, 2018, p. 18). Incorporar essa dimensão ao construído, ao já feito é um dos lugares da literatura. É por meio dessa chave de compreensão que ele irá aproximá-la de outras artes ${ }^{5}$, entendendo-a como um elemento presente em todas as demais, e a todas estas superando, ao transformar suas limitações ${ }^{6}$ em valores positivos, e por fim produzindo uma "criativa nostalgia", sobretudo da realidade "que é o substrato de toda representação" (AIRA, 2017, p. 18).

Esse mecanismo muito se assemelha à construção onírica ${ }^{7}$, onde muitas vezes entre o sonho, espaço fora do tempo, e a realidade "há uma diferença, mais notável quanto menor é o contraste entre um e outra" (AIRA, 1990, p. 66). Nesses casos, a diferença está refletida na arquitetura, que já em si é um "reflexo entre o que se construiu e o que se construirá" (AIRA, 1990, p. 66).

Em Os fantasmas, Aira se vale a todo momento da trama que transcorre num edifício de luxo em construção no bairro de Flores, em Buenos Aires, para refletir sobre o potencial simbólico dessa dimensão do não construído, empreendendo um caleidoscópico giro de referências que passam por modelos de construção de tribos africanas e comunidades aborígenes, até chegar ao espaço urbano latino, em especial argentino.

\footnotetext{
${ }^{4}$ AIRA, César. Os fantasmas. Rio de Janeiro: Rocco, 2017, p. 66.

5 "Todas as artes têm uma base literária, fundida na sua história e no seu mito". Os fantasmas, p. 67.

6 "Es cierto que queda algo así como un vacío insalvable: falta el sonido material que tiene la música, o los colores de la pintura, los volúmenes de la escultura, las imágenes en movimiento del cine... Pero la novela utiliza positivamente esa falta, como deliciosa y creativa nostalgia de la imagen y el sonido (...) la novela ha quedado, como resto inasimilable, el sistema entero de las artes, su historia, su arqueología, como significante de lo real que está a punto de nacer, o de volver". "Evasión", p. 17-18.

7 "E enquanto que os hábitos, sedentários ou nômades, são feitos de tempo, os sonhos estão livres dele. O sonho é espaço puro, disposição da espécie na eternidade. A partir desse ponto, o não construído, matéria mental sem tempo, sai do campo da possibilidade." Os fantasmas, p. 71.
} 
A imagem da maquete torna-se central em seus argumentos, e parece se fixar como uma de suas ideias-fixas como ficcionista/ensaísta, retornando em diversos de seus textos ${ }^{8}$. É, porém, neste "entre-espaços" (nem maquete, nem edifício finalizado), que as ações são encenadas por seus personagens, que percorrem aquela espacialidade provisória, que é estrutura, mas ainda não acabamento ${ }^{9}$, e que se configura, como veremos adiante, num modo de ilha urbana, como a define Josefina Ludmer:

O regime territorial urbano latino-americano contém em seu interior outros tipos de formas. As cidades brutalmente divididas do presente têm em seu interior áreas, edifícios, habitações e outros espaços que funcionam como ilhas, com limites precisos." (LUDMER, 2013, p.130).

A ilha urbana latina, como a quer Josefina, é um modo de ler essa estranha espacialidade ocupada pela família do chileno Raúl Viñas, protagonista da ficção de Aira. Seus membros, ao mesmo tempo em que convivem com as limitações impostas pela precariedade do edifício em obras (excessivamente quente, sem ventilação, com improvisadas instalações elétricas e hidráulicas ${ }^{10}$ ), assim como em tantas outras das "cidades-miséria" ${ }^{11}$ do continente, estão instalados e usufruem do afluente bairro de Flores ${ }^{12}$. Vivem nessa dinâmica entre estar dentro e estar fora, entre o que falta e a abundância, oposições que deixarão de fazer sentido quando a construção estiver concluída e o provisório tornar-se definitivo.

\footnotetext{
${ }^{8}$ Seria realmente saboroso escrever sobre as maquetes na obra de Aira, imagem potente que ajuda a entender o processo de construção da escrita ficcional, método para produção de espacialidades e a transposição do plástico para o literário.

9 "Depois da não construção, e como sua forma de constituição lógica (vale dizer antes da não construção), vem a construção. Em sua face real, a construção é a decoração. A decoração em arquitetura é sempre uma ampliação, uma ampliação de tudo e de qualquer coisa, da qual só o que se retém é o processo de ampliação.” Os fantasmas, p. 76.

10 "Os pisos não tinham lajotas, nem o forro gesso, nem as paredes pintura, nem os banheiros os artefatos, nem as janelas vidros. Mas havia água e eletricidade trazida por uma linha precária". Idem, p. 37.

${ }^{11} \mathrm{O}$ termo é utilizado originalmente pelo historiador e urbanista norte-americano Mike Davis no artigo "Planet of Slums - Urban Involution and the informal proletariat", In: New Left Review, v-26, mar.-abr. 2004.

${ }^{12}$ É curioso notar que o bairro de Flores, em 1990, quando Aira lança Os fantasmas, ainda possibilitava dinâmicas que se davam pelo contraste - os que estão fora mesmo estando dentro -, algo assemelhado a exemplos brasileiros como Paraisópolis, favela incrustrada no afluente bairro do Morumbi, em São Paulo, e a Cruzada São Sebastião, conjunto habitacional no bairro do Leblon, no Rio de Janeiro. Hoje, mais de um quarto de século após o lançamento do romance, Flores se transformou numa das regiões mais violentas de Buenos Aires, com altas taxas de homicídios, intensa atividade do narcotráfico, disputas de gangues, confecções clandestinas e bordeis que se valem de mão de obra em condições assemelhadas à escravidão. É como se na cidade oficial o espaço intermediário entre o dentro e o fora, como propõe Aira, tenha sido desmobilizado e substituído pela invasão violenta das práticas rotineiras da cidade-miséria latino-americana, tornando-se território específico, pintado em cores próprias que o diferencia nos mapas que medem as estatísticas sociais.
} 
Aira opera em um registro que corre em paralelo a essa dimensão material da espacialidade construída. A caracterização intervalar entre o projeto e sua versão final ganha as notas de um processo libertário. É como se Aira, diante da cidade latina violentamente dividida, criasse o último espaço possível para os que estão fora dos limites da cidade oficial (que ainda reproduzem as dinâmicas da antiga oposição entre o urbano e o rural): o espaço do ainda não concluído, que iguala a todos, ou ainda melhor, faz com que os que estão habitualmente fora e acostumados com aquilo que nunca se conclui, com o que nunca está inteiramente pronto (o puxadinho, a gambiarra), se sintam confortáveis, como é confortável para a família de Viñas, com suas crianças que brincam com seus carrinhos pelos andares em obras, sua mulher e enteada, que fazem compras pelo bairro, ou dedicam-se à sesta diária. Ao passo que os que estão dentro (a trupe de futuros moradores, arquitetos, decoradores, que visitam o edifício no último dia do ano), sentem a tensão do não concluído, a expectativa incômoda dos que ainda estão fora, mesmo que estejam habilitados pelo direito adquirido da propriedade a estar dentro. Tensão interessante essa que Aira expõe, inversão no jogo de poder da cidade oficial.

A família Viñas habita o precário, embora instalada no último andar da construção - local destinado ao espaço de lazer do edifício, em mais uma das inversões de Aira -, e está de tal forma habituada com o que não se define por completo, em conviver com corpos que são mais como abstrações, tanto o corpo planejado do edifício ainda não realizado, quanto o corpo dos homens que, vítimas de uma onda de calor abrasivo, parece ganhar outra espécie de materialidade (o corpo também passa a ser uma precariedade, não tem acesso aos atenuadores modernos, precisa improvisar abanadores, não se refugia no ar condicionado potente), que mantém uma convivência sem sobressaltos com o grupo de fantasmas ${ }^{13}$ que habita o edifício, e que, longe de qualquer caracterização sobrenatural, parece normalizado na precariedade da sociedade argentina.

O que já está feito e o que está por fazer, o projeto (a maquete) e a obra feita, se confundem. Abre-se um imenso campo de exploração entre a potência e a realização, em que o que não está concluído é tão importante quanto o já produzido, faz parte deste, o constitui, como realização e impossibilidade.

\footnotetext{
13 Seria realmente estimulante poder escrever sobre essa presença fantasmática na obra de Aira. Ora surgindo de modo explícito como nesta ficção, ora funcionando como metáfora ou modo de articulação como em suas menções ao museu e suas obras que "durante séculos esperaram em seus lugares para que fôssemos ver (...) só falam quando alguém lhes dirige a palavra, e são eminentemente sedentários”. Sobre a arte contemporânea, p. 17.
} 


\section{I - O tecido urbano é um relato / Construir maquetes}

"La superficie, después de todo, es el camino más disponible para un buen escape,
y es con superficies como se construyen volúmenes habitables". César Aira

No método literário de que César Aira ${ }^{14}$ se vale para criar espacialidades, construir maquetes (reais ou figuradas) é poder avançar além da pura narração, produzir volumes, densidades, construir o cenário para aqueles que habitam suas narrativas. No seu ensaio Sobre a arte contemporânea, lançado no Brasil em 2018, ele irá recuperar uma passagem de Mario Praz sobre o pintor francês Nicola Poussin, que permite ilustrar seu próprio modo de pensar suas ficções. Praz diz que:

O encanto dos quadros de Poussin consiste em acharem-se imbuídos com a lembrança de uma experiência tátil, e em banharem-se na luz estranha, quase de aquário, de um presépio. Poussin tinha visto realmente, com os olhos da mente, a cena romana, grega ou bíblica que estava pintando; tinha visto todos os seus detalhes, como foram no momento em que o fato histórico aconteceu; de certo modo havia tocado os corpos e os vestidos dos personagens. Esse método era quase o de uma reconstrução arqueológica. (AIRA, 2018, p. 16).

Esse método de que trata Praz consiste em desenhar esboços, produzir maquetes com um detalhamento obsessivo, habitá-las com seres produzidos em cera, e partir dessa materialidade, em que se vê o modo exato como a luz incide e as sombras se desenham, para construir suas representações pictóricas, que mais se assemelham a uma arqueologia da memória do trabalho de suas próprias mãos.

Cabe agora fazer com que essa capacidade de projetar e construir espacialidades possa se expandir e ocupar os complexos territórios da cidade latino-americana. Pensar como, além dessa organização de interiores, de cenas, que obedece às mesmas regras do mundo material, esta pode operar sobre essas espacialidades que se espalham como um tecido rugoso, repleto de involuções que mais podem ser pensadas como ilhas.

No repertório de ficções que Ludmer analisa, essas ilhas mantêm uma relação de encerramento e contaminação com a cidade oficial. Um pêndulo entre estar dentro e

14 "La novela que no era sólo la narración de una historia sino la construcción de la escena de una historia (...) esa novela (...) era una espécie de maqueta con resortes, poleas, luces, telones que se deslizan, miniaturas dotadas de chips parlantes...La narración-construcción implicaba un trabajo, una artesanía que costaba trabajo: no era simplesmente ponerse a contar algo." "Evasión”, p. 32. 
fora da lei (há uma lei própria nesses espaços ${ }^{15}$ ), em que seus habitantes tomam parte de uma comunidade que "reúne todas as demais" (LUDMER, p. 2013, p. 119). Essa ilha, podemos pensar, pode funcionar como as maquetes que tanto fascinam César Aira. Espaços tridimensionais, em escala real, "um regime territorial de significação (...) que coloca corpos em relação com territórios, fixa posições, e traça movimentos." (LUDMER, 2013, p. 120).

Talvez na urbe latino-americana evadir-se seja mais do que um procedimento estético, e sim uma proposta ética. Menos pela possibilidade de um espaço que se inventa como realidade, ou como a câmara de escape que o prazer da leitura propicia, e mais com o que revela em sua intensa capacidade de construir espaços, em dar a ver o que muitas vezes não passa de sombra ou rasura. Ocupar o território além do registro oficial e dos cartões-postais, com luzes, paredes, corredores, escadarias, e preenchê-los de subjetividades que usualmente se mantêm borradas. Relatar o que se passa na superfície movediça, em que se negocia diariamente o modo como se dá a vida. Encarnações nacionais da dinâmica globalizada, como a socióloga holandesa Saskia Sassen propõe ${ }^{16}$, em que seus habitantes "parecem ter perdido a sociedade ou algo que a representa" (LUDMER, 2013, p. 119).

O método de Ludmer é especular através da literatura, perceber como a imaginação pública ${ }^{17}$ relata esses espaços e os corpos que por eles movimentam-se, deslizam, chocam-se, vivem em territórios operados sob novas formas. As "formas de territorialização", propõe Ludmer, "são instrumentos conceituais: diagramas, delimitações e topologias com sujeitos." (LUDMER, 2013, p. 109-110, grifo meu). O território passa a ser "uma delimitação do espaço" (IDEM, p. 110). Nesse encontro entre o método representacional de Aira e as reflexões pós-autonomia da literatura de Ludmer, talvez seja possível encontrar um modo de repensar o espaço latino-americano, encontrar um modo de ouvir as vozes que tentam escapar das posições predeterminadas em que as pretendem aprisionar ${ }^{18}$ nessas ilhas.

\footnotetext{
15 "A ilha é um mundo com regras, leis e sujeitos específicos". Aqui, América Latina, p. 118.

16 "Um dos efeitos da globalização econômica é a produção de novas espacialidades e temporalidades, que pertencem tanto ao nacional como ao global. É nas cidades que a globalização econômica encarna nacionalmente". APUD LUDMER, Josefina. Aqui, América Latina, p. 160.

17 “(...) um universo sem exterior, real virtual (a virtualidade é o elemento tecnológico), de imagens e palavras, discursos e narrações, que flui num movimento perpétuo e efêmero". Aqui, América Latina, p. 9.

18 "O ser da literatura seria o ser da língua onde esta se furta às ordenações que dão aos corpos, vozes próprias para colocá-los em seu lugar e em sua função: uma perturbação na língua análoga à perturbação democrática dos corpos quando só a contingência igualitária os põe juntos". RANCIËRE, Jacques. A política da escrita, p. 31 .
} 
Ludmer diz que estas têm limites, mas estão abertas, como se fossem públicas. Creio que a ideia faça sentido no conjunto de textos ficcionais e não-ficcionais produzido em torno do ano 2000, de que ela se vale para construir seu corpus. Porém, em determinados territórios que extrapolam esse recorte temporal, e que povoam obras que emergem ou fazem referência ao período de suspensão da democracia no continente, é preciso que se pontue outras dinâmicas que se dão nessa espacialidade.

As ilhas latinas desse espaço em que o pacto da democracia foi rompido, embora mantenham-se desenhadas nos mapas territoriais da cidade, não passam de convenções em que sua comunidade passa a ter vedado o direito de circular, movimentar-se entre o dentro e fora. São ilhas fechadas, territórios de confinamento, a quem a saída simbólica, a dimensão do não construído que César Aira opera em Os fantasmas, não pode ser acessada sequer como a possibilidade de um devaneio ou procedimento de evasão (ou escape). Essas espacialidades agem sob leis específicas e diferem do regime que Ludmer retira de narrativas literárias e não literárias latino-americanas da virada do milênio. Nesses espaços confinados não é possível que "o segredo, a intimidade e a memória se tornem públicos" (LUDMER, 2013, p. 9). Pelo contrário, o veto a que estes vazem do interior dos corpos e da experiência e alcance a imaginação pública é um de seus principais propósitos.

Não se trata apenas do conjunto de regras que um determinado território passa a obedecer e que anulam as mediações diárias que marcam o convívio comunitário, mas como uma lei imposta como oficial (a suspensão da lei do regime de exceção, a legislação às avessas ${ }^{19}$ ) se vale dessas espacialidades para impor políticas públicas, alterações nos modos de convívio, exclusão de determinados grupos, cartilhas de comportamento, restrições à fala e a censura do que pode ser lido ou escrito. Nesses espaços de confinamento, a abertura à dimensão pública com a qual Ludmer opera ${ }^{20}$ está vedada, e mais se assemelha ao mecanismo do sonho, como o descreve Aira, mas em chave negativa: lugar onde cessa o tempo, em que se refina a partir de recorrências a matéria do pesadelo que se vive diariamente de olhos abertos.

Esses territórios confinados se constituem em regimes de exceção, mas podem extrapolar e constituir ilhas de cerceamento produzidas por políticas sanitárias,

\footnotetext{
${ }^{19}$ Agamben analisando o momento imediatamente posterior ao 11/09 formula de forma clara a questão: "A partir do momento em que o estado de exceção tornou-se a regra, ele não só sempre se apresenta muito mais como uma técnica de governo do que como uma medida excepcional, mas também deixa aparecer sua natureza de paradigma constitutivo da ordem jurídica”. Estado de exceção, p. 18.

20 “O público é o que está fora e dentro, como íntimo público. Na especulação não sobra nada dentro; o segredo, a intimidade e a memória se tornam públicos”. Aqui, América Latina, p. 9.
} 
perseguições religiosas, ideológicas ou processos de exclusão e extermínio de determinados grupos. Sua espacialidade é a mais diversa: hospitais psiquiátricos e prisões, políticas de sistemas de educação ou saúde, redes públicas de transporte na metrópole, mas também podem ser campos de refugiados e acampamentos de guerrilha, como o Araguaia (em que a des-diferenciação se inverte, não é o rural que vaza e se mistura ao urbano, mas o urbano que escorre pelo interior do continente como uma mancha de contenção que se alastra). São ainda aquilo que se desnaturaliza dentro da própria cidade, espaços que perdem sua função de origem, sua identidade multifacetada, seu lugar na imaginação pública, e que repentinamente se fraturam sob o peso da ocupação de uma nova ordem autoritária. Espaços como o da universidade pública, como por exemplo a UnB de começo dos anos 1970, representada em A noite da espera, primeira parte da trilogia O lugar mais sombrio, de Milton Hatoum.

\section{II - Um continente confinado}

Em A noite da espera, o tempo é o período final dos anos 1960 e o começo dos anos 1970. O espaço é Brasília, na maior parte das vezes a UnB e o Centro de Ensino Médio ligado à universidade. Estamos no momento mais brutal da ditatura civil-militar pós-AI-5, e o grupo de jovens, que gira em torno do protagonista Martim, sente na pele os efeitos da transformação do território público da universidade em campo de confinamento.

Essa transformação se dará em vários níveis. Instala-se na palavra, nas ideias que passam a ser monitoradas, cerceadas, apagadas ${ }^{21}$, e que passam a circular ora como código cifrado, senhas entre os que se conhecem ${ }^{22}$, ora como tentativa de ação política no caso do grupo, a criação de uma revista de humanidades produzida com o apoio financeiro do pai de um dos integrantes, e que acabará por motivar diversas detenções entre os seus colaboradores. Desdobra-se no confronto físico e num confinamento tanto territorial quanto temporariamente em deslocamento - camburões, ônibus que recolhem

\footnotetext{
21 "A censura excluiu cinquenta e duas frases e substituiu várias palavras"(...) "Dois estudantes queriam queimar todos os livros doados pelo embaixador (...) o cara queria tocar fogo em tudo (...)" HATOUM, Milton. A noite da espera, p.116 e 132.

22 "Eu e um amigo selecionamos os convidados e pedimos sigilo a todos. Alguém revelou a senha a uma pessoa que pode ser um delator. Posso reconhecer o penetra, mas é impossível saber quem deu a senha para ele.” Idem, ibidem, p. 161-162
} 
os estudantes ${ }^{23}$-, antes de ganhar uma nova espacialidade específica (a delegacia, a triagem, a cela). Por fim há a interdição do território, perde-se a possibilidade de circulação, a dinâmica de liberdade dos corpos entre o dentro e o fora, substituída pela imobilidade. $\mathrm{O}$ espaço se transforma pela força de uma violência que apaga os rostos e os corpos - "me perdi numa nebulosa cinzenta que cobria a escola e as pessoas, civis e militares" (HATOUM, 2017, p. 147). Perde-se a localização espacial, a geografia se altera: "Não conseguia andar, a poeira grudava na minha pele, os pés afundavam numa areia pardacenta" (HATOUM, 2017, p. 147). Até que a modificação do território físico ganha o campo simbólico, se subjetiva: "O jogo de vida e morte é outro. A UnB está morrendo, a escola onde vocês estudaram foi fechada" (HATOUM, 2017, p. 198). Nesta ilha, delimitada pelas forças do Estado de exceção, inverte-se a especulação de Ludmer: deixa de ser possível mover-se, escapar das posições em que o sujeito é colocado (a não ser pela fuga ou exílio), e a possível "perturbação democrática dos corpos" quando estão juntos (RANCIÈRE, 1995, p. 31) transforma-se em apagamento de distinções, de identidades; das diferenças entre corpos enfileirados, amontoados em camburões; em gestos coreografados pelo poder - braços erguidos, mãos levadas à nuca, filas indianas, cabelos raspados.

O que se impõe é a permanência de um trauma que se afirma numa perene suspenção de possibilidades, pelo assombro da dor ${ }^{24}$ incessante de uma potência não mais possível de ser cumprida, e do veto ao prazer - aquele que "se conclui perpetuamente em ato" (AGAMBEN, 2012, p. 61). Nesse espaço ocupado de modo violento, o poder repousa sobre "as forças que obrigam a potência a permanecer em si mesma" (AGAMBEN, 2012, p. 61); a autoridade onipotente bloqueia o desfecho do que se inicia; impede que aquele que parta, venha a chegar; inibe a presença dos corpos onde quer que queiram estar presentes.

Josefina Ludmer diz que a ilha urbana latino-americana é construída para ser temporária, tendo por intuito final sua própria destruição e o abandono de seus habitantes; assim é o espaço ocupado pelos personagens de César Aira, que vivem na precariedade de uma obra em construção que deixará de existir assim que concluída,

23 "O ônibus para a Asa Sul parou no começo da W3, bloqueada (...) vi a Escola Parque e a praça Vinte e um de Abril, cercadas por viaturas policiais (...) "Os estudantes vão fazer passeatas e comícios, o pau vai comer nessa bagunça". "Na invasão do campus, a polícia prendeu dezenas de universitários e saqueou o barracão da Federação dos Estudantes da UnB"(...) "Meus amigos e outros participantes da [revista] Tribo, enfileirados, de braços erguidos ou com as mãos na nuca, entravam devagar num camburão" Idem, p. 40,48 e 228.

24 “(...) a potência é o contrário do prazer. Ela é aquilo que nunca está em ato, que sempre falha o seu objetivo; em suma é a dor". AGAMBEN, Giorgio. Ideia da prosa, p. 61. 
decorada, habitada por seus proprietários. A potência nesses registros se dá pelas intensas demandas do provisório, que completa seu ciclo com sua extinção libertária. Porém, há uma outra versão dessa ilha. Em relatos como A noite da espera, os corpos não são mais livres e potentes para abandonar, voltar a habitar ou constituir novas ilhas numa cadeia de possibilidades encadeadas e incessantes; o provisório deixa de ser delimitado, ilhado, espalha-se muito além da espacialidade de uma cidade ainda inacabada ${ }^{25}$, inconclusa, sem centro, "onde o centro era toda a cidade" (HATOUM, 2017, p. 27). Não é mais possível representá-la na tridimensionalidade da maquete, pois ela perde sua característica insular e se espraia por todo território nacional, visto de fora apenas por meio da bidimensionalidade dos mapas; mapas de um continente confinado.

Confinados material e simbolicamente neste continente, os corpos passam a circular entre o dentro e fora apenas quando conduzidos pela violência de novos Atos impetrados pela prepotência de um poder que deseja transformar à força o temporário em definitivo ${ }^{26}$. Essa fantasia louca os esgota, extingue, extermina, e seus fantasmas, longe de estarem naturalizados pela precariedade da comunidade latina, como propõe César Aira, possuem carne, ossos, desejos, e jamais conseguem mover-se entre as paredes do território em que se veem trancafiados.

\section{Bibliografia}

AGAMBEN, Giorgio. Estado de exceção. 2a ${ }^{\text {a }}$ ed. São Paulo: Boitempo Editorial, 2004. AGAMBEN, Giorgio. Ideia da prosa. Belo Horizonte: Autêntica Editora, 2012. AIRA, César. Evasión y otros ensayos. Barcelona: Random House, 2017. AIRA, César. Os fantasmas. Rio de Janeiro: Editora Rocco, 2017. AIRA, César. Sobre a arte contemporânea. Rio de Janeiro: Zazie Edições, 2018. DAVIS, Mike. Planet of Slums. Nova York: Verso, 2006.

GASPARI. Elio. A ditadura envergonhada. São Paulo: Companhia das Letras, 2002. HATOUM, Milton. A noite da espera. São Paulo: Companhia das Letras, 2017.

\footnotetext{
25 "Esses edifícios da Asa Norte foram construídos às pressas. A pintura da fachada desbotou, o reboco é uma porcaria, já está estufado. Inauguraram uma cidade que ainda é um canteiro de obras". A noite da espera, p. 28.

26 "No dia 11 de abril, depois de um conciliábulo de governadores e generais destinado a evitar a coroação de Costa e Silva, o general Humberto de Alencar Castello Branco foi eleito presidente da República pelo Congresso Nacional, como mandava a Constituição. Prometeu “"entregar, ao iniciar-se o ano de 1966, ao meu sucessor legitimamente eleito pelo povo em eleições livres, uma nação coesa"”. Em 1967 entregou uma nação dividida a um sucessor eleito por 295 pessoas." Gaspari, Elio. A ditadura envergonhada, p. 125.
} 
LUDMER, Josefina. Aqui, América Latina: Belo Horizonte: Editora UFMG, 2013.

RANCIÈRE, Jacques. A política da escrita. São Paulo: Editora 34,1995.

Data de Recebimento: 02/10/2018

Data de Aprovação: 15/12/2018 


\section{Para citar essa obra:}

GODÓY, José Roberto Araújo de. A construção de espaços confinados na literatura latino-americana. In: RUA [online]. Volume 25, número 1 - p. 87-98 - e-ISSN 21799911 - junho/2019. Consultada no Portal Labeurb - Revista do Laboratório de Estudos Urbanos do Núcleo de Desenvolvimento da Criatividade.

http://www.labeurb.unicamp.br/rua/

Capa: detalhe da capa do livro Evasión y otros ensayos. De César Aira. Disponível em: https://images.livrariasaraiva.com.br/imagemnet/imagem.aspx/?pro_id=102 $80917 \& q \mathrm{ld}=90 \& \mathrm{l}=430 \& \mathrm{a}=-1=1005606593$

Laboratório de Estudos Urbanos - LABEURB

Núcleo de Desenvolvimento da Criatividade - NUDECRI

Universidade Estadual de Campinas - UNICAMP

http://www.labeurb.unicamp.br/

Endereço:

LABEURB - LABORATÓRIO DE ESTUDOS URBANOS

UNICAMP/COCEN / NUDECRI

CAIXA POSTAL 6166

Campinas/SP - Brasil

CEP 13083-892

Fone/ Fax: (19) 3521-7900

Contato: http://www.labeurb.unicamp.br/contato 